\title{
Kedilerin Önemli Bakteriyel Zoonozu: Helicobacter heilmannii
}

\author{
Güvenç GÖKALP* Ayșe Birsen GÖKALP \\ Yozgat Bozok Üniversitesi Veteriner Fakültesi İ̧̧ Hastalıkları Anabilim Dalı, Yozgat, Türkiye \\ Erciyes Üniversitesi Veteriner Fakültesi Mikrobiyoloji Anabilim Dall, Kayseri, Türkiye
}

Atıf yapmak için: Gökalp, G. \& Gökalp, A.B. (2021). Kedilerin Önemli Bakteriyel Zoonozu: Helicobacter heilmannii. Anadolu Çev. ve Hay. Dergisi, 6(3), 333-340.

How to cite: Gökalp, G. \& Gökalp, A.B. (2021). Significant Zoonotic Bacteria of Cats: Helicobacter heilmannii. J. Anatolian Env. and Anim. Sciences, 6(3), $333-340$.

https://orcid.org/0000-0001-9249-3567 (iD) : https://orcid.org/0000-0002-3405-6040
*Sorumlu yazarin:

Güvenç GÖKALP

Yozgat Bozok Üniversitesi Veteriner

Fakültesi İç Hastalıkları Anabilim Dalı,

Yozgat, Türkiye

凶: guvenc.gokalp@yobu.edu.tr
Öz: Kedilerde zoonotik karaktere sahip olan Helicobacter heilmannii bakterisinin hem hayvanda hem de insanda görülme sıklığı sadece olgular dahilinde literatürlerce belirtilmiş bununla ilgili daha geniş bir hastalık ve etken taraması yapılmamıştır. Kedi sahipleri veya kedilerle aynı çevreyi paylaşan insanlarda bu bakterinin varlığı ve olası yaygınlığı gözardı edilmemelidir. Edinilen bulgularda göre $H$. heilmannii, insanlarda mukoza ilişkili lenfoid doku lenfoması (MALT)'ın olası nedenleri arasında gösterilmektedir. Şimdiye kadar yapılan çalışmalarda insanlardaki $H$. heilmannii insidansının kedilere nazaran daha az olduğu ve bulaşmanın genellikle kedilerden insanlara doğru seyir gösterebileceği görüşü yaygınlaşmaktadır. Zoonotik karaktere sahip olan $H$. heilmannii klinik belirtiler açısından diğer gastrik kökenli helikobakterlere benzerlik gösterebilmektedir. Enfekte kedilerde klinik olarak insanlardakine benzer tipik kronik aktif gastritis belirtileri görülebilmektedir. Helikobakter kökenli enfeksiyonların teșhisinde çeșitli yöntemler bulunmaktadır. Erken dönemdeki teșhiste Üre nefes testi, PCR, üreaz testi ve gastrik biyopsi yöntemlerinin yaygın olarak kullanıldığı bilinmektedir. Helicobacter heilmannii'nin ise etkene ait karakteristik morfolojisinin belirlenmesinde mikrobiyolojik tanı yöntemlerinden olan boyama yöntemleri kullanılmaktadır. Helicobacter heilmannii'den kaynaklı gastritislerin tedavi prosedürleri ise diğer helikobakter türlerinden kaynaklı gastritis tedavilerine benzerlik göstermektedir. Son olarak ise hastalığın takibi açısından uygulanan tedavi prosedürlerinin üç ay aralıklarla etken taraması yapılarak tekrarlanabileceği unutulmamalıdır. Bu derleme makalesi kedilerde bulunması muhtemel ve zoonoz olabilen $H$. heilmannii'nin halk sağlığı açısından önemine vurgu yapmayı amaçlamaktadır.

Anahtar kelimeler: H. heilmannii, kedi, malt, tedavi, teșhis, zoonoz.

\section{Significant Zoonotic Bacteria of Cats: Helicobacter heilmannii}

\footnotetext{
*Corresponding author's: Güvenç GÖKALP

Yozgat Bozok University, Faculty of

Veterinary Medicine, Department of Internal

Medicine, Yozgat, Turkey

凶: guvenc.gokalp@yobu.edu.tr
}

\begin{abstract}
The incidence of Helicobacter heilmannii bacteria, which has a zoonotic character in cats, in both animals and humans has only been reported in the literature within the scope of the cases, and a wider disease and agent screening has not been performed. The presence and possible prevalence of this bacterium in people who share the same environment with cat owners or cats should not be ignored. According to the findings obtained, H. heilmannii is shown as one of the possible causes of mucosaassociated lymphoid tissue lymphoma (MALT) in humans. In studies conducted so far, it is widely believed that the incidence of $H$. heilmannii in humans is lower than that of cats and thansmission can generally progress from cats to humans. H. heilmannii, which has a zoonotic character, may be similar to other gastric-derived helicobacteria in terms of clinical symptoms. The typical chronic active gastritis symptoms clinically similar to those in humans can be seen in infected cats. There are various methods for diagnosing Helicobacter infections. It is known that Urea breath test, PCR, urease test and gastric biopsy methods are widely used in early diagnosis. Staining methods, one of the microbiological diagnosis methods, are used to determine the characteristic morphology of Helicobacter heilmannii. The treatment procedures of gastritis caused by Helicobacter heilmannii are similar to the treatments for gastritis originating from other helicobacter species. Finally, it should be kept in mind that the treatment procedures applied in terms of the follow-up of the disease can be repeated by screening agents at intervals of three months. This review article aims to emphasize the importance of $H$. heilmannii in terms of public health, which can be found in cats and may be zoonotic.
\end{abstract}

Keywords: Cat, diagnosis, H. heilmannii, malt, treatment, zoonosis. 


\section{GİRIŞ}

Helikobakter türlerinin kolonizasyonu ile gastritise ve mide ülserine sahip hasta köpek ve kediler arasında birebir bağlantı bulunmamaktadır. İnsanlarda ve evcil hayvanlarda görülen Helicobacter pylori, gastrit ve mide ülserinin önemli bir nedeni olarak görülse de $H$. pylori dışındaki Helikobakter türlerinin köpek ve kedilerde mide patojeni olarak rolü daha az bilinmesine karşın yaygın görülebilmektedir. Buna bağlı olarak, Helikobakter türlerinden $H$. heilmannii, $H$. pylori, $H$. felis ve $H$. bizzozeronii etkenleri ise farklı derecelerde gastritisli köpeklerden ve kedilerden izole edilebilmektedir (Tolbert \& Gould, 2020). Helicobacter heilmannii sensu lato grubu, hayvanların midesini doğal olarak kolonize eden uzun, spiral şekilli bakteri bakterilerden oluşmaktadır (Liu vd., 2014). Hasebrouck vd., (2011) yaptıkları çalışmada, H. heilmannii sensu lato terimi tüm $H$. pylori olmayan helikobakterler (NHPH )'in ifade edilmesinde önerilmiştir. Bu etkenler insan ve hayvan midesinde histopatoloji, elektron mikroskobu ve ham taksonomik DNA tabanlı verilerle tespit edilmiştir. Helicobacter heilmannii sensu stricto terimi ise tür düzeyindeki bakteriyi ifade etmektedir (Hernandez vd., 2016). NHPH'lerin mide sağlığı açısından klinik önemi giderek artmaktadır. Bu bakteri grubunun, kediler, köpekler, domuzlar, primatlar, kemirgenler, çitalar ve tavşanlar dahil olmak üzere evcil ve vahşi hayvanların midesinde yaşayabilen, hayvanlar ve insanlar arasında geçiş yapabilen zoonotik özellikteki mikroorganizmalar olduğu bilinmektedir (Nakamura vd., 2016).

Spiral şekilli olmayan, H. pylori dişındaki Helikobakter türlerinin insan mide mukozasını da kolonize ettiği belirlenmiştir. İnsanlarda görülme sıklıkları ise $\% 0,1$ ile 6,2 arasında değişmektedir (Berlamont vd., 2020). Helicobacter heilmannii ise insan midelerinde nadirde olsa $\%$ 0,1-2 oranlarda görülebilen bakteriyel bir ajandır (Ostahi vd., 2017). Van den Bulck vd., (2005) yaptıkları çalışmada bulunan en yaygın türün $H$. suis $(\% 37)$ olmasının yanında bunu $H$. salomonis (\%21), H. felis (\%15), H. heilmannii (\%8) ve $H$. bizzozeronii (\%4) izlemektedir (Flahou vd., 2016). Helicobacter heilmannii enfeksiyonu insidansı, insanlar arasındaki tüm Helikobakter enfeksiyonlarının yaklaşı \%1'ini oluştursa da sosyoekonomik durumu zayıf ülkelerde görülme sıklığının çok daha yüksek olduğu bilinmektedir (Majumber vd., 2020). Yapılan çalışmalarda ise $H$. heilmannii insanlarda semptomatik hastaların \%5'inde bulunmasına karşın $H$. heilmannii tarafindan oluşturulan kolonizasyonlardaki farklılıklar ile pylori negatif ve pylori pozitif hastalar arasındaki ilişkinin baz alındığ herhangi bir çalışma yapılmamıştır (Nakamura vd., 2016; Mladenova vd., 2017; Mohammadi vd., 2019).

Etiyoloji: Helikobakter türleri Gram (-), mikroaerobik, hareketli, fuziform, spiral şekilli veya spiral çubuk morfolojisine sahip olabilen bakterilerdir. Farklı türleri arasında sayısı ve bulunduğu yere göre değişkenlik gösteren flagellalarını kullanarak hareket edebilmektedir (Hong vd., 2015). Yüz elli omurgalı hayvanlardan alınan dışkı örneklerinde Polimeraz Zincir Reaksiyonu (PZR) ile 45 Helikobakter türü tespit edilmiştir (Elyasi vd., 2020). Helicobacter heilmannii ise \%20-100 arasındaki prevalans oranları ile köpek ve kedilerin mide mukozalarını doğal olarak kolonize edebildiği bilinmektedir (Kubota vd., 2017; Matos vd., 2020). 16S rRNA gen dizilerinin analizi sonucu $\% 96,6$ benzerlik oranlarına rağmen $H$. heilmannii tip 1 ve tip 2 olarak sınıflandırılma yapılmış, morfolojik açıdan benzer organizmalar genellikle kedilerdeki $H$. felis, köpeklerdeki $H$. bizzozeronii ve $H$. salomonis, domuzlardaki ise $H$. suis olarak adlandırılmıştır (Ülgen vd., 2016).

Helicobacter heilmannii ve $H$. felis' in dahil olduğu H. pylori dışındaki Helikobakter türleri, H. heilmannii benzeri organizmalar (HHLO'lar) olarak da adlandırılmaktadır (Goji vd., 2015). Gastrospirillum hominis'in gastrik kökenli olan $H$. heilmannnii'nin ilk adı olduğu bilinmektedir (Mladenova vd., 2017). Helicobacter heilmannii ismi yapılan sekans analizleri sonucu bulunan 16S rRNA geni ile bu bakterinin mide mikroorganizmalarından Helikobakter cinsine ait olduğu belirlendikten sonra verilmiştir (Joosten, 2017). Helicobacter heilmannii mikroskobik tanım açısından $H$. pylori'nin sahip olduğu spiral morfolojiye benzemektedir. Helicobacter pylori 2,5-4 mm uzunluğunda iken, $H$. heilmannii ise 7-10 mm uzunluğundadır. Helicobacter heilmannii ise hücre başına dört ile altı dönüşlü spiral yapıya ve kutup başına 12 flagellaya kadar sahip olabilmektedir (Hernandez vd., 2016).

Kedilerde H. heilmannii: Kedilerdeki ana gastrik Helikobakter türleri öncelikle $H$. heilmannii ve $H$. felis'tir. $\mathrm{Bu}$ iki türün kedilerde prevalansının \%57 ile 100 arasında olduğu bildirilmiştir (Hong vd., 2016). Helikobakter enfeksiyonlarının köpek veya kedi grupları arasındaki bulaşması kesinlik kazanmamasına bağlı olarak rezervuar konakçıları da tanımlanmamıştır. İnsanlarda Helikobakter enfeksiyonlarına bağlı elde edilebilen morbidite ve mortalite oranları zoonotik bulaşma riskinin artabileceğini göstermektedir (Blois, 2020).

Kedi ve köpeklerde yaygın olarak görülebilen ve $H$. heilmannii tip 2 grubunda bulunan $H$. salomonis'in insan midesinde de sıkça kolonize olabildiği bilinmektedir (Liu vd., 2014). Helicobacter spp prevalansinın \%41-100 oranlarında olmasına karşın baskın türler olan H. heilmannii ve $H$. felis, subglandüler ve gastrik mukozada hafif veya şiddetli diffuz lenfoplazmasitik infiltrasyona neden olabilmektedir (De sousa vd., 2019).

Helicobacter heilmannii'nin Helicobakter spp. pozitif vakalı olan kedilerle, gastrik hastalığı olan hasta insanlardan izole edilen Helikobakter türleri arasında \% 99 
oranında sekans benzerliği tespit edilmiştir (Kubota vd., 2017). Helicobacter heilmannii enfeksiyonu kronik aktif gastrit ile ilişkilendirilmiş olsa da köpeklerde ve kedilerde gastrit, peptik ülserasyon ve kronik kusma açısından değerlendirildiğinde bu hayvan türleri için patojenik önemi netlik kazanmamıştır ancak etkenin suşuna bağlı olarak enfeksiyonun patojenitesi değişkenlik gösterebilmektedir (Matos vd., 2020).

Helicobacter heilmannii enfeksiyonu ile birlikte MALT lenfoma: $H$. heilmannii sensu lato grubu bakterilerinin insan mide biyopsi örneklerinin \%0,2-6'sinda gözlendiği ve insanlarda kronik gastrit, peptik ülser ve gastrik düşük dereceli mukozayla ilişkili (MALT) ile ilişkilendirilmektedir (Liu vd., 2014). Helicobacter heilmannii'nin yüksek düzeydeki metabolizmasına bağlı olarak çok yönlü ve farklı çevresel etkilere tepki verme yeteneğine sahip olması insanlarda $H$. heilmannii enfeksiyonunun zoonotik doğasının temelini oluşturduğunu göstermektedir (Mladenova vd., 2017). Helicobacter pylori dışındaki Helikobakter türleri birçok hayvanın midesinde kolonize olsa bile ancak bazıları zoonotik potansiyel gösterebilmektedir. Özellikle kedi ve köpeklerle bulunabilen $H$. suis ve $H$. heilmannii etkenleri, gastritis, mide veya duodenum ülseri veya MALT lenfoması olan hasta insanlarda tespit edildiği bilinmektedir (Berlamont vd., 2020). Helicobacter heilmannii etkeni H. pylori'ye kiyasla gastrik MALT lenfomalarının oluşumunda daha fazla rol oynamaktadır. Helicobacter pylori esas olarak mukozal tabakayı kaplarken, $H$. heilmannii ise antral bezlerin derinliklerine kadar yayılım gösterebilmektedir (Shafaie vd., 2020). Nodüler yapılı gastritis vakalarının \%40'1nda, MALT lenfoma vakalarının \%24'ünde, kronik gastiritislerin $\% 17$ 'sinde ve gastroduodenal ülser vakalarının \%33'ünde Helikobakter türleri açısından pozitiflik saptandığı bildirilmektedir (Nakamura vd., 2020). İnsanlarda ise benzer semptoma sahip hastalara yapılan mide biyopsilerinin \%819'unda $H$. heilmannii'ye rastlanılmaktadır (Bahadori vd., 2018; Matos vd., 2020).

Nakamura ve arkadaşlarının yaptıkları bir çalışma ise farelerde deneysel olarak oluşturulan $H$. heilmannii ilişkili gastritisin sadece midede değil aynı zamanda hepatik ve pulmoner kökenli MALT lenfomayı da tetikleyebildiğini göstermektedir (Sikiric \& Brzozowski, 2020). Tedavi protokollerinde kullanılan antibiyotiklerden, özellikle klaritromisinin potansiyel immünomodülatör veya hatta doğrudan anti-neoplastik etkilerinin olabileceği ve bu yolla eradikasyon tedavisi açısından önemli katkıda bulunabileceği bildirilmektedir. Ayrıca kullanılan bu antibiyotiklerin, aynı zamanda MALT lenfoma gelişimi ile bağlantılı olan $H$. heilmannii gibi $H$. pylori dışındaki mikroorganizmaları da ortadan kaldırabileceği öngörülmektedir (Jung vd., 2021).
Klinik Bulgular: NHPH enfeksiyonları ile ilişkili klinik semptomlar arasında akut veya kronik epigastrik ağrı, mide bulantısı, dispepsi, reflü özofajit, mide ekşsimesi, kusma, hematemez, abdominal ağrı, düzensiz dışkılama, dışkı kıvamında ve iştahta azalmanın eşlik ettiği disfajinin bulunduğu bilinmektedir (Flahou vd., 2016). Bu semptomların yanısıra ot yeme, sarkık pozisyonda kalma, kaprofaji, allotriofaji, anokreksi, ruktus ve meteorizm gözlenmektedir (Ülgen vd., 2016). Helicobacter heilmannii enfeksiyonu sadece klinik bulgulara bakılarak gıdaya duyarlı enteropatiler, bakteriyel hipertrofi, IBD (Yangısal Barsak Hastalığı) veya parazitik enteropati gibi olgularla karıştırılabilmektedir (Rychlik \& Kaczmar, 2020). Helicobacter heilmannii enfeksiyonu ile gözlenen gastrit, $H$. pylori'ye bağlı olandan daha az şiddetli olma eğilimindedir (Mladenova vd., 2017).

Mide kaynaklı helikobakterler, midede herhangi bir klinik semptom göstermeden bulunabilmekte, ancak safra kanalında firsatçı patojen özellik kazanabilmektedir (Takemura vd., 2019). Hem sağlıklı hem de hasta köpek ve kedilerde Helikobakter'in yüksek prevalans göstermesi, bu hastalığın klinik önemi ve teşhisi açısından köpek ve kedilerde belirsizliğe neden olabilmektedir (Blois, 2020). Kronik kusma, Helikobakter enfeksiyonundan muzdarip kediler ve köpekler için açıklanan temel klinik bulgudur. İnsanlarda olduğu gibi kedi ve köpeklerde görülebilen Helikobakter türleri, kronik aktif gastritis ile gastrik kökenli lenfoma ise $H$. heilmannii enfeksiyonu ile ilişkilendirilmektedir (Joosten, 2017).

Tani: Helikobakter enfeksiyonunu saptamak için farklı düzeylerde duyarlılık ve özgüllükte invaziv veya noninvaziv tekniklerin kullanıldığı çeşitli teşhis yöntemleri geliștirilmiştir. İnvaziv yöntemler, histoloji, kültür ve mide doku biyopsilerinin kullanıldığı hızlı üreaz testi ile endoskopik yöntemlerden oluşmaktadır. İnvaziv olmayan testler arasında üre nefes testi ve fekal antijen testleri biyopsi temelli tekniklerle karşılaştırılaştırıldığında doğru sonuca hızlı ulaşabilen teşhis prosedürleri olarak görülmektedir. Ayrıca, bu testlerin tedavi sürecinin takibi açısından tercih edilebilecek yöntemlerden olduğu bilinmektedir (Sabbagh vd., 2019).

Enfeksiyöz etiyolojilerin histopatolojik veya immünohistokimyasal açıdan tanımlanmasını gerekmektedir. Kedilerde ve köpeklerde Helikobakter ile ilişkili gastritis mide biyopsilerinden yapılan floresan in situ hibridizasyon (FISH) PZR uygulamaları kesin tanı açısından önemini korumaktadır (Tolbert \& Gould, 2020). Dişk1 antijen testi, Helikobakter eradikasyonunu doğrulamakta yararlı görülse bile poliklonal antikorların kullanıldığı test tipinin tanısal doğruluğu diğer tanı yöntemlerine göre düşük olabileceği düşünülmektedir. Dışkı antijen testi'nin, üre nefes testi kadar tanısal açıdan benzer doğruluğa sahip olabilmesi için test tipinde monoklonal antikorların 
kullanımı önerilmektedir (Shiotani vd., 2016). Kubota vd., (2005) yaptıkları bir çalışmada $H$. heilmannii tanısına gitmek için yapılan ureAB genlerinin sekans analizleri sonucu $H$. heilmannii etkeninin neredeyse tüm Helikobakter-pozitif vakalarda büyük oranlarda tespit edildiği ve bu nedenle farklı NHPH ile enfekte olgular arasında gastrik histopatolojik tanıların bir karşılaştırmasının yapılamayacağı bildirilmektedir (Kubota vd., 2017). Köpeklerde ve kedilerde kronik enfeksiyon şeklinde seyreden gastrointestinal sistem hastalıklarında gastroduodenoskopi ve kolonoskopi ile kombinasyon halinde uygulanabilen endoskopik yöntemlerin teşhis açısından etkili olduğu bilinmektedir (Rychlik \& Kaczmar, 2020). Endoskopik yöntemler, özellikle peptik ülser olgularına bağlı olarak Helikobakter varlığının belirlenmesinde kullanılan en etkili yöntemlerdir. Bununla birlikte, endoskopi, non-invaziv testlerden daha riskli olabilmekte ve uygulama esnasında birçok hasta için rahatsızlık verebilmektedir (Alzoubi vd., 2020). Hızlı üreaz testleri mide biyopsilerinde bakteriyel üreaz üretiminin saptanmasına bağlı olarak Helikobakter varlığının tespitinde kullanılan testlerdir. Ancak, hızlı üreaz testleri gibi biyopsi temelli olan histopatolojik testler ise tanısal açıdan hızlı üreaz testlere nazaran daha duyarlı ve spesifik testlerdir (Blois, 2020). Hizlı üreaz testlerinin prensibi bakteriyel üreazın üreyi amonyak ve karbondioksite ayrıştırması özelliğine dayanmaktadır. Bu yöntemde Helikobakter içeren bir mide biyopsisi üre içeren bir ortama yerleştirildikten sonra bakteriyel üreaz tarafindan üretilen amonyağın $\mathrm{pH}^{\prime} 1$ yükseltmesi ile birlikte $\mathrm{pH}$ indikatöründe renk değişikliğinin oluşmasına bağlı olarak bakteri varlığı tespit edilmektedir (Shiotani vd., 2016).

Üre Nefes Testi: Üre nefes testi (ÜNT), Helikobakter kökenli enfeksiyonların tanısında en çok önerilen, invaziv olmayan, yüksek duyarlılık ve özgüllüğe sahip bir yöntemdir (Hong vd., 2016). ÜNT, yaklaşık \%95'lik duyarlılık ve özgüllük gösterebilen doğru teşhis yöntemi olarak kabul edilmektedir (Atkinson \& Braden, 2016). ÜNT, patojenin yok edilip edilmediğinin belirlenmesinde güvenilir ve değerli bir yöntem olduğu bilinmektedir. Testin uygulanmasında öncelikle işaretlenmiş izotop içeren üre ağız yoluyla verilmektedir. Daha sonra, Helikobakter etkeni varlığında midede üretilen bakteriyel üreaz ölçümü yapılmaktadır. Bunun yanında, kanda ve solunum havasındaki karbondioksit miktarları ise kütle spektrofotometre yöntemiyle ölçülebilmektedir (Sabbagh vd., 2019). Kütle spektrometresinin yanısıra dağılmayan izotop seçici kızılötesi spektroskopi yöntemi de üre nefes analizinde kullanılabilmektedir (Atkinson \& Braden, 2016). Bunun yanında, Helikobakterin üreyi hidroliz edebilme özelliğine dayanan işaretlenmiş karbon atomu uygulamasında radyoaktif izotop olan $\mathrm{C}^{14}$ veya radyoaktif olmayan $\mathrm{C}^{13}$ izotopları kullanılmaktadır. $\mathrm{Bu}$ izotoplarla işaretli üre etkenin ürettiği üreaz enzimi ile parçalanması sonucu açığa çıkan karbondioksitin solunum havasında saptanması esasına dayalı bir yöntem de bulunmaktadır (Gökalp, 2013).

Genellikle, H. pylori etkenli enfeksiyon teşhisi için kullanılan ÜNT, $H$. heilmannii ile enfekte hastalarda negatif çıkabilmektedir. Bu durum NHPH bakterilerinden kaynaklı enfeksiyonlarının, H. pylori enfeksiyonlarının aksine, daha sıklıkla fokal yolla bulaşmasından ve ağırlıklı olarak midenin antrumunda bulunmasından dolayı bu test türler arasındaki sınırlı tanısal değerleri ortaya koyabilmektedir (Joosten, 2017). NHPH kaynaklı olduğu bilinen enfeksiyonlarda ÜNT'inin hem negatif hem de zayıf pozitif sonuçlar verebilmesi üre nefes testinin NHPH kaynaklı enfeksiyonların tespitinde uygulanmasını zorlaştırmaktadır (Nakamura vd., 2020). Ağız boşluğu veya mideden izole edilen Klebsiella pneumoniae, Staphylococcus aureus, Proteus mirabilis, Enterobacter cloacae ve Citrobacter freundii gibi çeşitli mikroorganizmalar da üreaz aktivitesi göstermekte ve yanlış pozitif sonuçlar vermektedir (Sabbagh vd., 2019). ÜNT'i, köpek ve kedilerde Helikobakter tedavi sürecinin takibinde kullanılmaktadır. Kombine uygulanan tedavi prosedürlerinden sonra kusma ve benzeri belirtilerin tekrar etmesi halinde tedavi sürecinin kontrol edilmesi açısından yeniden uygulanacak olan ÜNT'rinin yanında mide biyopsisi temelli uygulamalar da yapılmalıdır (Takemura vd., 2019). Enfeksiyon için uygulanan üçlü tedavi prosedürünü bitirdikten yaklaşık 6 hafta sonra eradikasyonun sağlanıp sağlanılmadığını öğrenebilmek için ÜNT'i ile dışkı antijen testlerine ihtiyaç duyulmaktadır (Alzoubi vd., 2020). Bazı çalışmalar ÜNT'inin gastritis, özofagus patolojileri ve ülserlerin varlığını doğrulayamadığını belirtmesine rağmen, bu test hastalığın erken teşhisi ve tedavi sürecinin etkin olabilmesi açısından dışkı antijen testi de dahil olmak üzere diğer birçok invazif olmayan testler arasından tercih edilmektedir (Sabbagh vd., 2019).

Mikrobiyolojik Tanı: Helikobakter türleri arasında ilk olarak kedilerin midesinden izole edilen ve köpeklerde de spiral şeklinde kolonileşmeyi yapan tür H. felis'tir (Nakamura vd., 2016). Helicobacter heilmannii ile benzerlik gösteren $H$. felis' in yanında $H$. bizzozeronii ve $H$. salomonis de kedi ve köpeklerden izole edilmektedir (Mladenova vd, 2017). 16S rRNA dizisinin analizi ile $H$. heilmannii' in tip 1 ve tip 2 alt siniflandirmalarının yapilmasindan sonra, $H$. suis'in $H$. heilmannii tip 1 'i temsil eden tek tür olduğu ve H.felis, $H$. bizzozeroniii, $H$. salomonis, $H$. cynogastricus, $H$. baculiformis ve asıl $H$. heilmannii türlerinin ise $H$. heilmannii tip 2' yi temsil ettiği bildirilmektedir (Hernandez vd., 2016). H. heilmannii, H. pylori ile karşılaştırıldığında $H$. heilmannii'nin olduğu daha uzundur ve insandaki karakteristik morfolojisi ise hematoksilin-eosin, Giemsa veya gümüş boyama ile görülebilmektedir. $H$. 
heilmannii'nin özellikle midenin antrumunda bulunduğu ve touch smear sitoloji ile daha iyi teşhis edilebildiği bilinmektedir (Ostahi vd., 2017).

PZR analizlerinde H.pylori ve NHPH (H. suis, $H$. heilmannii, $H$. felis, $H$. bizzozeronii ve $H$. salomonis ) 'lere ait DNA ekstraksiyonları kullanılmaktadır. H.pylori için ureC geninin amplifikasyonu, NHPH türleri için de ureA geninin amplifikasyonu uygulanmakta ve DNA varlığının doğrulanması için de pozitif olan tüm örneklerde sekans analizi yapilabilmektedir (Bahadori vd., 2018). Helikobakter ile enfekte hayvanların mide dokusunda, sirasıyla CagA proteinini kodlayan cagA ve ureC sekansları ve üreazın alt birimi C, Polimeraz Zincir Reaksiyonu ile tespit edilebilmektedir (Gonciarz vd., 2021). Antibiyogramı yapılmış kedi izolatlarının çoğunda ampisilin, klaritromisin ve tetrasikline karşı direnç görülmesine rağmen $H$. felis pozitifliği olan örneklerde ise metronidazole karşı direnç görülmektedir (Goldstein \& Abrahamian, 2015). Gastrik biyopsi muayenesinin morfolojik yönden teşhiste önemli olduğu bilinmektedir. Helicobacter heilmannii'nin karakteristik morfolojisi ise Hematoksilen-Eozin, Giemsa veya Warthin-Starry ile boyanmış biyopsi örneklerinde tanımlanabilmektedir (Goji vd., 2015)

Tablo 2. Helicobacter heilmannii'nin diğer gastrik Helikobakter türlerine kıyasla morfolojik ve biyokimyasal özellikleri (Joosten vd., 2016).

\begin{tabular}{|c|c|c|c|c|c|c|}
\hline Helikobakter Türleri & Uzunluk $(\mu \mathrm{m})$ & Periplasmik fibril & Flagella dağılımı & Üreaz aktivitesi & Nitrat üretimi & $\begin{array}{c}\text { Alkalin Fosfataz } \\
\text { aktivitesi }\end{array}$ \\
\hline H. heilmannii & $3-6,5$ & - & Bipolar & + & + & - \\
\hline H. felis & $5-7,5$ & + & Bipolar & + & + & + \\
\hline H. bizzozeronii & $5-10$ & - & Bipolar & + & + & + \\
\hline H. salomonis & $5-7$ & - & Bipolar & + & + & + \\
\hline H. pylori & $2,5-5,5$ & - & Monopolar & + & - & + \\
\hline
\end{tabular}

Bahadori vd., (2018) yaptı̆̆ histopatolojik analiz için alınan biyopsilerin $\% 10$ fosfat tamponlu formalin'de sabitlendikten sonra, rehidre edildiği ve $5 \mu \mathrm{m}$ 'de kesitli parafin içinde gömüldükten sonra parafinden arındırılarak hematoksilin ve eozin (HE) ile boyanarak 1ş1k mikroskobik altında incelendiği ve elde edilen boyanmış gastrik biyopsilerde ise eğri şekilli veya spiral şekilli formlarda helikobakterlerin varlığının gözlemdiği bildirilmiştir (Bahadori vd., 2018). Dışkı antijen testinde ise dışkı örneklerindeki Helikobakter spesifik antijeni, bir enzim immünoassay veya immünokromatografi kullanılarak bakteri varlığı açısından saptanabilmektedir. İmmünokromatografik özellikteki dışkı antijen testlerinde laboratuvar ekipmanına ihtiyaç duyulmamaktadır. Monoklonal dışkı antijen test kitlerinin duyarlılığı poliklonal teknikten daha yüksek olduğu ise bilinmektedir (Atkinson \& Braden, 2016).

Tedavi: Helikobakter etkenleri etkin antimikrobiyal tedavinin yokluğunda mideyi kolonize ettikten sonra bir ömür boyu konakçıda yaşayabilmektedir (Joosten vd., 2017). Helikobakter enfeksiyonlarında uygulanan gastrik biyopsi muayenesi enflamasyon derecesinin belirlenmesinde, enflamatuar ve neoplastik lezyonların (iyi huylu veya kötü huylu) ayırt edilmesinde ve uygulanan herhangi bir tedavi prosedürünün değerlendirilmesinde kullanılabilmektedir (Rychlik \& Kaczmar, 2020). Helikobakter enfeksiyonlarının tedavisi için antibiyotikler ve asit baskılayıcılardan oluşan kombinasyon tedavi önerilmektedir. Köpek ve kedilerdeki Helikobakter kaynaklı enfeksiyonlar için uygulanacak tedavi şekilleri ise Helikobakter varlığında ortaya çıkabilen uygun klinik semptomlar ve mide lezyonlarının birlikte değerlendirilmesine göre değişkenlik gösterebilmektedir (Blois, 2020).
Tedavide kullanılan proton pompası inhibitörleri, antibiyotikler ve bizmut bileşikleri kombinasyonu yanıltıcı negatif sonuçlara neden olabilmektedir (Sabbagh vd., 2019). Helicobacter heilmannii tedavisi, ciddi klinik bulguları ve patolojisi olan insan hastalar için de endike olabileceği bilinmektedir. Günümüzde $H$. heilmannii tedavisi $H$. pylori eradikasyonu için kullanılan üçlü tedavi prosedürü ile aynıdır. Üçlü terapi prosedürü metronidazol veya amoksisilin ile birlikte iki antimikrobiyal ajan olan klaritromisin ve tetrasiklin ile omeprazol gibi bir proton pompası inhibitörünü içermektedir (Joosten, 2017). Köpek ve kedilerdeki gastrik Helikobakter spp. enfeksiyonlarının tedavisinde insanlardakinden farklı olarak asit supresyon takviyesine gerek duyulmadığı ancak bizmut türevlerinin tedaviye dahil edilmesinin gerekli olabileceği belirtilmektedir (Gökalp, 2013). Kedi izolatlarının çoğu ampisilin, klaritromisin ve tetrasikline duyarlıdır, oysa iki Helikobakter suşu metronidazole karşı direnç göstermektedir (Goldstein \& Abrahamian, 2015). Bizmut veya bizmut içermeyen terapi modelinin (proton pompa inhibitörü, tetrasiklin, metronidazol ve bizmut tuzu) klaritromisine veya metronidazole karşı direncin olduğu durumlarda yararlı olabileceği bilinmesine rağmen bu modeldeki çoklu antibiyotik kullanımında tedavi sürecinin uzamasına bağlı olarak da antimikrobiyal direncin artabileceği bildirilmektedir (Garcia vd., 2021). Tedavinin değerlendirilmesinde hasta hayvandan alınan dışkı örneklerinden genomik DNA ekstraksiyonu uygulanmaktadır. Etkende bulunan üreaz $\mathrm{B}$ geninin çoğaltılmasında için de bir multipleks Helikobakter spesifik PZR testi yapılmaktadır. Hastalığın takibi açısından bu uygulama hasta hayvanlarda antibiyotik tedavisinden üç ay sonra tekrarlanabilmektedir (Hong vd., 2015). 


\section{Zoonotik Önemi: Kedilerden insanlara} bulaşabilecek veya muhtemelen kediler ve insanların ortak yaşam alanlarından kaynaklardan edinebilecekleri çok sayıda hastalık bulunmaktadır. Bununla birlikte, evcil kedinin henüz tanımlanmamış birçok zoonoz için potansiyel rezervuar olabileceği bilinmektedir (Goldstein \& Abrahamian, 2015). Helicobacter heilmannii'nin gelişmiş ülkelerde \%0,5, Doğu Avrupa ve Asya ülkelerinde ise $\% 1,2-6,2$ arasında değişebilen düşük prevalanslara sahip olduğu bilinmektedir (Mladenova vd., 2017). Kedilerin ve köpeklerin, gastrik Helikobakter türleri için rezervuar konak olmasından dolayı zoonotik potansiyel göstermektedir. Köpek ve kedilerde görülen $H$. pylori dışındaki helikobakter türlerinin zoonotik potansiyeli bir dizi vaka çalışması ile belirlenmektedir. Helicobacter heilmannii' deki zoonotik potansiyel ise bu etkenin kedilerden sahiplerine doğrudan temas yoluyla bulaşabilmesinden kaynaklanmaktadır (Joosten, 2017).

Tablo 3. Kedilerde görülen Gastrik Helikobakter türleri ve bulunduğu konaklar (Joosten, 2017).

\begin{tabular}{lcc}
\hline Takson & Doğal Konak & Zoonotik Potansiyeli \\
\hline H. baculiformis & Kedi & Bilinmiyor \\
H. bizzozeronii & Kedi, Köpek & Var \\
H. elis & Kedi, Köpek,Tavşan & Var \\
H. heilmannii & Kedi, Köpek, Domuz & Var \\
H. salomonis & Kedi, Köpek,Tavşan & Var \\
\hline
\end{tabular}

Helicobacter heilmannii'nin görülme sıklı̆̆ının değişkenliği bulaşma kaynağı açısından çeşitliliğin olduğunu göstermektedir. Öte yandan, $H$. heilmannii'nin insanlarda görülen gastrointestinal hastalıklar ile bağlantılı olduğu ve bunun histopatolojik bulgularla desteklenebildiği bilinmektedir (Shafaie vd., 2020). Evcil hayvanların midesinde, sütünde ve etinde insanlarda görülen helikobakter türlerindeki vacA genotiplerine benzer yüksek miktarda suşlarının bulunması hayvansal kaynaklı gıdalardan da Helikobakterlerin bulaşabileceğini göstermektedir (Park vd., 2020). Gastritise ait klinik belirtiler gösteren insanlarda yapılan endoskopik muayenelerde biyopsi sonucu Helikobakter türlerinin tespit edildiği ve bu türler arasinda $H$. heilmannii'ye rastlanıldığı belirtilmektedir (Majumber vd., 2020). Ayrıca $H$. heilmannii tip 1 olarak adlandırılan $H$. suis, insana en çok bulaşan $H$. pylori dışındaki Helikobakter türlerinden olduğu bilinmektedir. Kedi ve köpeklerde baskın halde bulunan ve $H$. heilmannii tip 2 olarak adlandırılan $H$. felis, $H$. bizzozeroniii, $H$. salomonis, $H$. cynogastricus, $H$. baculiformis ve asıl $H$. heilmannii türlerinin ise $H$. heilmannii tip 1'e göre daha az oranda zoonotik etkisi olduğu belirtilmektedir (Nakamura vd., 2016).

Korunma: Helikobakter enfeksiyonunu veya bununla ilişkili patolojileri önlemeye yönelik bazı yeni yaklaşımların olduğu ve bu bağlamda Saccharomyces, Lactobacillus ve Bifidobacterium spp. gibi probiyotik kullanımlarının proflaktik etki yaratabileceği doğrulanmaktadır. Gelecekteki araştırmalarda, Helikobakter enfeksiyonu ile ilişkili hastalıkların önlenmesinde ve tedavisinde yeni stratejilerin potansiyel değerlerinin belirlenmesi ve antimikrobiyal direnç konusuna durumlara odaklanmanın önemi bilinmektedir (Pere Vedrenne vd., 2017). Immunoglobulin G antikorlarının tedaviden sonraki aylarda saptanabilmesi ve bu nedenle bakteriyel klirensten sonra bile pozitif sonuç verebilmesi dikkate alınmaktadır (Sabbagh vd., 2019). Tedavide kullanılan antimikrobiyal ajanların etken direncini arttırması eradikasyon tedavisinde yıllar boyunca daha az başarı elde edilmesine ve aşılama benzeri alternatif yaklaşımlara ihtiyaç duyulmasına neden olabilmektedir (Pan vd., 2018). Profilaktik ve terapötik aşılamanın, gastrik. Helikobakter enfeksiyonlarının önlenmesi ve tedavisi için en umut verici alternatif yaklaşım olduğu öngörülmektedir. (Joosten, 2017). Kanıtlar, aşılamada aşıların, farklı yollar, farklı antijenler ve adjuvantlardan oluştuğunu göstermektedir. Bu uygulamanın ise ülser ve mide kanseri riskinin azaltılmasında kullanılabileceği söylenmektedir. Tabii ki, aşılar söz konusu olduğunda, bazı aşılama stratejilerinin insanlarda test edildiği, ancak neredeyse hiçbir zaman eradike edici bağışıklığa ulaşamadığı bilinmektedir (Sabbagh vd., 2019).

Sonuç: Sonuç olarak, Helikobakter kökenli enfeksiyonların etken ve konak düzeyinde iyi sınıflandırılması gerekmektedir. Bunun için de sağlıklı anamnezin yanısıra teşhis metotlarının, insidans araştırmalarının, tedavi yaklaşımlarının ve zoonotik potansiyellerinin ciddi şekilde ele alınması önemlidir. Kedilerde görülen $H$. heilmannii'nin değerlendirilmesinde kedilerin yaşadığ 1 çevre koșulları ve beslenme alıșkanlıkları göz önünde bulundurulmalı hem kedi sahiplerinin hem de kedilerin sağlığını tehdit edebilen zoonoz karakter kazanmış olan $H$. heilmannii kökenli enfeksiyonların önüne geçebilecek etkin teşhis ve tedavi protokolleri oluş̧urulmalıdır.

\section{KAYNAKLAR}

Alzoubi, H., Al-Mnayyis, A., Al rfoa, I., Aqel A., AbuLubad, M. \& Hamdan, O. (2020). The Use of 13C-Urea Breath Test for Non-Invasive Diagnosis of Helicobacter pylori Infection in Comparison to Endoscopy and Stool Antigen Test. Diagnostics, 10(7), 448.

Atkinson, N.S.S. \& Braden, B. (2016). Helicobacter Pylori Infection: Diagnostic Strategies in Primary Diagnosis and After Therapy. Digestive Diseases and Sciences, 61(1), 19-24.

Bahadori, A., De Witte, C., Agin, M., De Bruyckere, S. \& Smet, A. (2018). Presence of gastric 
Helicobacter species in children suffering from gastric disorders in Southern Turkey. Helicobacter, 23, 1-6.

Berlamont, H., De Witte, C. \& Bauwens, E. (2020). Distinct transcriptome signatures of Helicobacter suis and Helicobacter heilmannii strains upon adherence to human gastric epithelial cells. Veterinary Research, 51(1), 62.

Blois, S. (2020). Helicobacter infection in small animals. MSD Manual Veterinary Manual, Erişim tarihi: 10.12.2020,

https://www.msdvetmanual.com/digestivesystem/diseases-of-the-stomach-and-intestinesin-small-animals/helicobacter-infection-in-smallanimals.

De Sousa, D.A., Da Silva, K.S.V.G.C., Cascon, C.M., Silva, F.B.F. \& De Mello, M.F.V. (2019). Epidermal growth factor receptor 2 immunoexpression in gastric cells of domestic cats with $\mathrm{H}$. heilmannii infection. Acta Histochemica, 121(4), 413-418.

Elyasi, B., Rezaie, A., Bakhtiari, N.M. \& Mosallanejad, B. (2020). Helicobacter genus in the intestine and liver of stray cats: the molecular, histopathological, and immunohistochemical study. Brazilian Journal of Microbiology, 51(4), 2123-2132.

Flahou, B., Haesebrouck, F. \& Smet, A. (2016). Helicobacter pylori Research, In: Backert, S. \& Yamaoka, Y. (Ed), Non-Helicobacter pylori Helicobacter Infections, 1st ed., 233-269p, Springer, Japan.

García, P.R., Van der Pol, S., Van Asselt, A.D.I., Postma, M., Rodríguez-Ibeas, R., JuárezCastelló, C.A., González, M. \& Antoñanzas F. (2021). Efficiency of Diagnostic Testing for Helicobacter pylori Infections-A Systematic Review. Antibiotics, 10(1), 55.

Goji, S., Tamura, Y., Sasaki, M., Nakamura, M., Matsui, H. \& Yamagata Murayama, S. (2015). Helicobacter suis-Infected Nodular Gastritis and a Review of Diagnostic Sensitivity for Helicobacter heilmannii- Like Organisms. Case Reports in Gastroenterology, 9(2), 179-187.

Goldstein, E.J.C. \& Abrahamian, F.M. (2015). Diseases transmitted by cats. Microbiology Spectrum, 3(5), $1-14$.

Gonciarz, W., Lechowicz, L., Urbaniak, M., Kaca, W. \& Chmiela, M. (2021). Use of Fourier-Transform Infrared Spectroscopy (FT-IR) for Monitoring Experimental Helicobacter pylori Infection and Related Inflammatory Response in Guinea Pig
Model. International Journal of Molecular Sciences, 22(1), 281.

Gökalp, G. (2013). Köpeklerde Helikobakter Enfeksiyonlarinin C14 Üre Nefes Testi ve Polimeraz Zincir Reaksiyonu (PCR) ile Belirlenmesi ve Tedavisi. Doktora Tezi, Ondokuz Mayıs Üniversitesi, Sağlık Bilimleri Enstitüsü. Samsun, Türkiye, 78s.

Hernandez, C., Serrano, C.A., Villagran, A., Torres, J., Venegas, A. \& Harris, P.R. (2016). Helicobacter pylori vacA virulence factor in uncultured Helicobacter heilmannii sensu lato from an infected child. JMM Case Reports, 3(2), 1-7.

Hong, S., Chung, Y., Kang, W.G., Cho,i Y.S. \& Kim, O. (2015). Comparison of three diagnostic assays for the identification of Helicobacter spp. in laboratory dogs. Laboratory Animal Research, 31(2), 86-92.

Hong, S., Chung, Y., Kang, W.G. \& Kim, O. (2016). Detection of Helicobacter felis in a cat with gastric disease in laboratory animal facility. Laboratory Animal Research, 32(2), 122-127.

Joosten, M., Lindén, S., Rossi, M., Tay, A.C.Y. \& Skoog, E. (2016). Divergence between the Highly Virulent Zoonotic Pathogen Helicobacter heilmannii and Its Closest Relative, the LowVirulence "Helicobacter ailurogastricus" sp. nov. Infection and Immunity, 84(1), 293-306.

Joosten, M., (2017). The zoonotic pathogen Helicobacter heilmannii from feline origin: aspects of virulence and gastric colonization. Ghent University, Faculty of Veterinary Medicine. Ghent, Belgium, 259s.

Jung, K., Kim, D.H., Seo, H.I., Gong, E.J. \& Bang, C.S. (2021). Efficacy of eradication therapy in Helicobacter pylori-negative gastric mucosaassociated lymphoid tissue lymphoma: A metaanalysis. Helicobacter, 00:e12774.

Kubota-Aizawa, S., Ohno, K., Kanemoto, H., Nakashima, K. \& Fukushima, K. (2017). Epidemiological study on feline gastric Helicobacter spp. in Japan. The Journal of Veterinary Medical Science, 79(5), 876-880.

Liu, J., He, L., Haesebrouck, F., Gong, Y. \& Flahou, B. (2014). Prevalence of Coinfection with Gastric Non-Helicobacter pylori Helicobacter (NHPH) Species in Helicobacter pylori-infected Patients Suffering from Gastric Disease in Beijing, China. Helicobacter, 20(4), 284-290.

Majumber, R., Mishra, P., Samal, S.C., Bhat, S.J. \& Patra, S. (2020). Helicobacter heilmannii associated gastritis: Report of a rare case. Indian 
Journal of Pathology and Microbiology, 63(3), 13.

Matos, R., De Witte, C., Smet, A., Berlamont, H., De Bruyckere, S. \& Amorim, I. (2020). Antimicrobial Susceptibility Pattern of Helicobacter heilmannii and Helicobacter ailurogastricus Isolates. Microorganisms, 8(6), 957.

Mladenova-Hristova, I., Grekova, O. \& Patel, A. (2017). Zoonotic potential of Helicobacter spp. Journal of Microbiology, Immunology and Infection, 50(3), 265-269.

Mohammadi, M., Abadi, A.T.B., Rahimi, F. \& Forootan, M. (2019). Helicobacter heilmannii Colonization Is Associated with High Risk for Gastritis. Archives of Medical Research, 50(7), 423-427.

Nakamura, M., Øverby, A., Murayama, S.Y., Michimae, H. \& Matsui, H. (2020). PCR analysis and specific immunohistochemistry revealing a high prevalence of non-Helicobacter pylori Helicobacters in Helicobacter pylorinegative gastric disease patients in Japan: High susceptibility to an Hp eradication regimen.

Helicobacter, 25(5), 1-13.

Nakamura, M., Øverby, A., Murayama, S.Y., Suzuki, H. \& Takahashi, T. (2016). Helicobacter pylori, In: Suzuki, H., Warren, R. \& Marshall B. (Ed). Gastric Non-Helicobacter pylori Helicobacter: Its Significance in Human Gastric Diseases, 1st ed., 131-142p, Springer, Japan.

Ostahi, I.A., Villanacci, V. \& Crisafulli, V. (2017). Human Helicobacter heilmannii-like organisms infection. 29th European Congress of Pathology, 2-6 September 2017, Amsterdam, The Netherlands, 25.

Pan, X., Ke, H., Niu, X., Li, S., Lv, J. \& Pan, L. (2018). Protection Against Helicobacter pylori Infection in BALB/c Mouse Model by Oral Administration of Multivalent Epitope Based Vaccine of Cholera Toxin B Subunit-HUUC. Frontiers in Immunology, 9, 1-12.

Park, H.S., Jeong, H.Y., Kim, Y.S., Seo, C.S. \& Kwon, H.J. (2020). Anti-microbial and antiinflammatory effects of Cheonwangbosim-dan against Helicobacter pylori-induced gastritis. Journal of Veterinary Sciences, 21(3), 1-15.

Péré-Védrenne, C., Flahou, B., Loke, M.F.\& Vadivelu, J. (2017). Other Helicobacters, gastric and gut microbiota. Helicobacter, 22(1), 1-7.

Rychlik, A. \& Kaczmar, E. (2020). Endoscopic Biopsies and Histopathological Findings in Diagnosing
Chronic Gastrointestinal Disorders in Dogs and Cats.Veterinary Medicine International. 1-8.

Sabbagh, P., Javanian, M., Koppolu, V. \&Vasigala, V.R. (2019). Helicobacter pylori infection in children: an overview of diagnostic methods. European Society of Clinical Microbiology, 38(6), 1035-1045.

Sabbagh, P., Mohammadnia-Afrouzi, M., Javanian, M. \& Babazadeh, A. (2019). Diagnostic methods for Helicobacter pylori infection: ideals, options, and limitations. European Journal of Clinical Microbiology \& Infectious Diseases, 38(1), 5566.

Shafaie, S., Kaboosi, H. \& Ghadikolaii, F.P. (2020). Prevalence of non Helicobacter pylori gastric Helicobacters in Iranian dyspeptic patients. BMC Gastroenterology, 20(1), 1-7.

Shiotani, A., Dore, M.P. \& Graham, D.Y. (2016). Helicobacter pylori, In: Suzuki, H., Warren, R. \& Marshall B. (Ed). Urea Breath Test and Rapid Urease Test, 1st ed.,143-155p, Springer, Japan.

Sikiric, P. \& Brzozowski, T. (2020). Physiological and Pharmacological Mechanisms in Gastrointestinal Protection, Ulcer Healing and Mucosal Repair-An Update. Current Pharmaceutical Design, 26(25), 2933-2935.

Takemura, L.S., Marcasso, R.A., Lorenzetti, E. \& Alfieri, A.A. (2019). Helicobacter infection in the hepatobiliary system and hepatic lesions: a possible association in dogs. Brazilian Journal of Microbiology, 50(1), 297-305.

Tolbert, K. \& Gould, E. (2020). Clinical Small Animal Internal Medicine, In: Bruyette, D.S. (Ed). Gastritis and Gastric Ulceration in Dogs and Cats, 1st ed., 547-557p, Wiley Blacwell, USA.

Ülgen, S., Ergin, S., Şennazlı, G. \& Bakırel, U. (2016). Detection of Helicobacter heilmannii type II and Helicobacter pylori in dogs and their role in the development of gastritis. Turkish Journal of Veterinary and Animal Sciences, 40, 81-88. 